\title{
Analisis distribusi obat pada pasien Badan Penyelenggara Jaminan Sosial (BPJS) di RSUP Prof. Dr. R. D. Kandou Manado
}

\author{
${ }^{1}$ Irene Liwu, ${ }^{2}$ Erwin G. Kristanto, ${ }^{3}$ Jerry G. Tambun
}

\author{
${ }^{1}$ Program studi Ilmu Kesehatan Masyarakat Bidang Minat Kajian Administrasi Rumah Sakit \\ Pascasarjana Universitas Sam Ratulangi Manado \\ ${ }^{2}$ Fakultas Kedokteran Universitas Sam Ratulangi Manado \\ ${ }^{3}$ Fakultas Hukum Universitas Sam Ratulangi Manado \\ Email: ireneliwu@yahoo.co.id
}

\begin{abstract}
The increasing quantity of BPJS patients (Social Security Administrator) leads the frequency of service for this program to increase. This study was aimed to analyze whether the drug distribution service reached the patients needs accurately (as prescribed), fast, and could reach the maximum level of cost efficiency in drug distribution process. This study was conducted at Prof. Dr. R. D. Kandou Hospital in Manado, a referral center hospital in East Indonesia. In this study, we used qualitative method. Data were obtained from several resources: BPJS's patients, doctors, nurses, pharmacy assistants, pharmacy helper, and head of the Department of Pharmacy. The qualitative data were obtained based on the comprehensive monitoring of the interview results and were further incorporated into the transcription by using snowballing sampling technique and triangulation. The results showed that the standard procedure of drug delivery regulation was not covered thoroughly due to the lack of time and perception of the pharmacy staff about the patient's need for information. Management of informative data is needed to support the distribution pathway including the order planning, eficiency of drug stock quantity, and handling of administrative data. Conclusion: The availability of drugs for BPJS patients at Prof. Dr. R. D. Kandou Hospital included in the distribution cycle was supported by optimum internal communication in acordance with accreditation standard and Permenkes pelayanan kefarmasian no. 72 tahun 2016.
\end{abstract}

Keywords: accuration, distribution, efficiency, frequency, procedure

\begin{abstract}
Abstrak: Meningkatnya kuantitas pasien yang masuk program Badan Penyelenggara Pelayanan Jaminan Sosial (BPJS) menjadikan frekuensi layanan untuk program ini ikut meningkat, khususnya untuk pelayanan obat. Penelitian ini bertujuan menganalisis layanan distribusi yang mampu menjangkau kebutuhan obat pasien dengan akurat (sesuai resep), cepat, dan dapat mencapai tingkat maksimum efisiensi biaya dalam proses distribusi obat. Penelitian dilakukan di RSUP Prof. Dr. R. D. Kandou Manado yang merupakan pusat rujukan rumah sakit di Wilayah Indonesia Timur. Penelitian ini menggunakan metode kualitatif yang diambil dari sumber informasi: pasien BPJS, dokter, perawat, asisten farmasi, tenaga bantu farmasi, dan kepala Departemen Farmasi. Data kualitatif diperoleh berdasarkan pemantauan komprehensif dari hasil wawancara yang dimasukkan ke dalam transkripsi dengan teknik sampel snowballing dan triangulasi. Hasil penelitian memperlihatkan adanya prosedur standar pemberian obat dari regulasi yang tidak tercakup menyeluruh dikarenakan faktor waktu dan persepsi tingkat kebutuhan informasi pasien dari tenaga farmasi. Diperlukan adanya penanganan data informasi yang mendukung jalur distribusi mulai dari perencanaan pemesanan obat, efesiensi kuantitas stok obat, dan pengelolaan data administrasi. Simpulan: Ketersediaan obat pada pasien BPJS di RSUP Prof. Dr. R. D. Kandou merupakan hasil rangkaian yang termasuk dalam siklus distribusi obat dengan dukungan komunikasi internal yang cukup dalam proses distribusi selaras dengan standar akreditasi dan Permenkes pelayanan kefarmasian no. 72 tahun 2016.
\end{abstract}

Kata kunci: akurasi, distribusi, efisiensi, frekuensi, prosedur 
Menurut Undang-undang No 44 tahun 2009 rumah sakit adalah institusi pelayanan kesehatan bagi masyarakat dengan karakteristik tersendiri yang dipengaruhi oleh perkembangan ilmu pengetahuan kesehatan, kemajuan teknologi, dan kehidupan sosial ekonomi masyarakat, yang harus tetap mampu meningkatkan pelayanan kesehatan yang lebih bermutu dan terjangkau oleh masyarakat agar terwujud derajat kesehatan masyarakat yang setinggi-tingginya. ${ }^{1}$

Rumah sakit umum adalah rumah sakit yang menyelenggarakan pelayan kesehatan kepada masyarakat untuk semua jenis penyakit, mulai dari pelayanan kesehatan dasar sampai dengan pelayanan subspesialis sesuai dengan kemampuan-nya. ${ }^{1}$ Pada implementasi jaminan kesehatan nasional (JKN) telah diatur pola pembayaran kepada fasilitas kesehatan tingkat lanjutan yaitu INA-CBGs sesuai dengan Peraturan Presiden nomor 12 tahun 2013 tentang jaminan kesehatan sebagaimana telah diubah dengan peraturan nomor 111 tahun 2013. Untuk tarif yang berlaku pada 1 Januari 2014, telah dilakukan penyesuaian tarif INA-CBGs jaminan kesehatan masyarakat (Jamkesmas) dan Peraturan Menteri Kesehatan (Permenkes) nomor 69 tahun 2013 tentang standar tarif pelayanan kesehatan pada fasilitas kesehatan tingkat pertama dan berkelanjutan dalam penyelenggaraan jaminan kesehatan. Tahun 2014 dikeluarkan Peraturan Menteri Kesehatan nomor 59 tahun 2014 tentang standar tarif pelayanan kesehatan dalam penyelenggaraan program jaminan kesehatan. ${ }^{2}$

Permenkes nomor 72 tahun 2016 menyatakan pelayanan kefarmasian adalah suatu pelayanan langsung dan bertanggung jawab kepada pasien yang berkaitan dengan sediaan farmasi dengan maksud mencapai hasil yang pasti untuk meningkatkan mutu kehidupan pasien. Instalasi Farmasi adalah unit pelaksana fungsional yang menyelenggarakan seluruh kegiatan pelayanan kefarmasian di Rumah Sakit. Distribusi obat merupakan suatu rangkaian kegiatan dalam rangka menyalurkan atau menyerah- kan sediaan farmasi, alat kesehatan, dan bahan medis habis pakai dari tempat penyimpanan sampai kepada unit pelayanan atau pasien dengan tetap menjamin mutu, stabilitas, jenis, dan ketepatan waktu. $^{3}$

Penelitian yang dilakukan oleh Yuliastuti dan Purnomo tentang penggunaan obat pada pasien rawat jalan di RSUD Sleman Yogyakarta periode April 2009 memperoleh hasil bahwa persentase ketersediaan obat yang sesuai dengan formularium rumah sakit pada pasien rawat jalan selama periode April 2009 sebesar $99,81 \%$. Hasil lainnya menyebutkan bahwa persentase obat yang benar-benar diberikan kepada pasien rawat jalan sebesar 99,04\%; persentase obat yang telah dilabel dengan benar pada pasien rawat jalan sebesar 98,06\%; dan persentase pasien rawat jalan yang paham akan cara penggunaan obat yang benar sebesar $85,42 \%$. Salah satu bagian penting dalam pelayanan pada pasien ialah obat yang harus diatur secara efektif dan efisien. Karena itu pendistribusian obat merupakan hal yang penting untuk mengurangi efek salah obat atau pasien yang tidak mengetahui penggunaan obat yang tepat dan pengurangan mutu pelayanan rumah sakit. ${ }^{4}$

RSUP Prof. Dr. R. D. Kandou dengan akreditasi A ialah rumah sakit rujukan yang ada di provinsi Sulawesi Utara, yang mendukung program pemerintah yaitu Jamkesnas. UU nomor 24 Tahun 2011 tentang Badan Penyelenggara Jaminan Sosial (BPJS) yaitu lembaga yang dibentuk untuk menyelenggarakan Program Jaminan Sosial di Indonesia. Pada pasien BPJS yang rawat jalan diberlakukan sistem resep perorangan. Dari data tahun 2015 jumlah kunjungan pasien rawat inap BPJS di RSUP Prof. Dr. R. D. Kandou pada bulan Januari-Desember 2015 sebanyak 29.965 pasien sedangkan untuk pasien rawat jalan sebanyak 108.841 pasien, dan untuk pasien rawat darurat sebanyak 36.920 pasien. Berdasarkan latar belakang di atas, penulis ingin mengkaji lebih lanjut bagaimana distribusi obat pada pasien BPJS di RSUP Prof. Dr. R. D. Kandou Manado. 


\section{METODE PENELITIAN}

Penelitian ini dilakukan dengan menggunakan metode kualitatif yang bertujuan untuk mendapatkan informasi yang lebih mendalam dengan melakukan analisis distribusi obat pada pasien BPJS di RSUP Prof. Dr. R. D. Kandou. Penelitian ini dilakukan di RSUP Prof. Dr. R. D. Kandou pada bulan Oktober-Desember 2016. Pengumpulan data dilakukan dengan cara wawancara mendalam kepada 15 informan yaitu pada pasien rawat jalan, pasien rawat khusus, pasien rawat inap, dokter, perawat, assisten apoteker, apoteker dan kepala instalasi. Pemilihan sampel pada penelitian ini berdasarkan prinsip kesesuaian (appropriateness) dan kecukupan (adequency). Validasi hasil penelitian dengan cara triangulasi sumber dan triangulasi teknik.

\section{HASIL PENELITIAN DAN BAHASAN Pemilihan obat pada pasien BPJS di RSUP Prof. Dr. R. D. Kandou.}

Telah dilakukan berdasarkan formularium dan standar pengobatan atau pedoman diagnosis dan terapi. Pola penyakit dan pengobatan berbasis bukti diminta dari setiap ruangan, ketersediaan di pasaran. Hasil penelitian ini mendapatkan obat yang benar-benar diserahkan sebesar 99,04\%, obat yang dilabel dengan benar sebesar $98,06 \%$, dan pasien yang paham akan cara penggunaan obat yang benar sebesar $84,42 \%$.

Penelitian ini sejalan dengan penelitian oleh Yuliastuti et al. ${ }^{4}$ tentang penggunaan obat pada pasien rawat jalan di RSUD Yogyakarta periode April 2009 yang mendapatkan bahwa persentase ketersediaan obat yang sesuai dengan formularium rumah sakit pada pasien rawat jalan selama periode April 2009 ialah 99,81\%.

\section{Perencanaan dan pengadaan obat pada pasien BPJS di RSUP Prof. Dr. R. D. Kandou.}

Perencanaan dipertimbangkan dengan anggaran yang tersedia, sisa persediaan, data pemakaian periode yang lalu, dan waktu tunggu pemesanan.
Hasil penelitian ini telah sesuai dengan Permenkes 72 tahun 2016. Perencanaan dilakukan untuk menghindari kekosongan obat dengan menggunakan metode yang dapat dipertanggungjawabkan dan dasardasar perencanaan yang telah ditentukan antara lain konsumsi, epidemiologi, kombinasi metode konsumsi dan epidemiologi, dan disesuaikan dengan anggaran yang tersedia. ${ }^{3}$ Fungsi perencanaan mencakup aktivitas dalam menetapkan sasaran, pedoman, pengukuran penyelenggaraan bidang logistik. Penentuan kebutuhan merupakan perincian dari fungsi perencanaan, dan bilamana perlu semua faktor yang memengaruhi penentuan kebutuhan harus diperhitungkan. ${ }^{1}$

\section{Penerimaan obat pada pasien BPJS di RSUP Prof. Dr. R. D. Kandou}

Pada penerimaan barang selalu terdapat panitia. Panitia penerimaan barang berjumlah 3 orang yang terbagi atas 2, yaitu medik dan non-medik untuk melakukan pemeriksaan jumlah, jenis, tanggal kadaluwarsa, dan kesesuaian nota pesanan, kemudian dilakukan penyimpanan.

Hasil penelitian ini telah sesuai dengan Permenkes 72 tahun 2016. Penerimaan merupakan kegiatan untuk menjamin kesesuaian jenis, spesifikasi, jumlah, mutu, waktu penyerahan, dan harga yang tertera dalam kontrak atau surat pesanan dengan kondisi fisik yang diterima. Semua dokumen terkait penerimaan barang harus tersimpan dengan baik. ${ }^{3}$

\section{Penyimpanan obat pada pasien BPJS di RSUP Prof. Dr. R. D. Kandou.}

Obat-obatan disimpan sesuai dengan tempat yang terjaga dan tertata dengan baik di rak sediaan, jenis tempat sesuai dengan golongan obat yang ada, dan suhu selalu dijaga.

Hasil penelitian ini sesuai dengan penelitian Ibrahim et al..$^{5}$ yang melaporkan bahwa pengelolaan persediaan farmasi dan perbekalan kesehatan lainnya dilakukan sesuai ketentuan perundangan yang berlaku meliputi: perencanaan, pengadaan, penyimpanan dan pelayanan obat yang 
memakai sistim FIFO (first in first out) dan FEFO (first expired first out). Pelayanan resep meliputi skrining resep yang berisi nama, surat ijin praktek dan alamat dokter, tanggal penulisan resep, tanda tangan atau paraf dokter penulis resep, nama dan umur pasien; kesesuaian bentuk sediaan, dosis, potensi, stabilitas, inkompatibilitas, eara dan lama pemberian; pertimbangan klinis adanya alergi, efek samping, interaksi, kesesuaian dosis dan jumlah obat. ${ }^{5}$

Menurut Sheina et al. ${ }^{6}$ indikator penyimpanan obat yaitu: 1) Kecocokan antara barang yang tersimpan dan kartu stok (stok dalam sistem): indikator ini digunakan untuk mengetahui ketelitian petugas gudang dan mempermudah dalam pengecekan obat serta membantu dalam perencanaan dan pengadaan obat sehingga tidak menyebabkan terjadinya akumulasi obat dan kekosongan obat; 2) Turn over ratio (TOR): indikator ini digunakan untuk mengetahui kecepatan perputaran obat, yaitu seberapa cepat obat dibeli, didistribusikan, sampai dipesan kembali, dengan demikian nilai TOR akan berpengaruh pada ketersediaan obat. TOR yang tinggi berarti mempunyai pengenda-lian persediaan yang baik, demikian pula sebaliknya, sehingga biaya penyimpanan akan menjadi minimal; 3) Persentase obat yang sampai kadaluwarsa dan atau rusak: indikator ini digunakan untuk menilai kerugian rumah sakit; 4) Sistem penataan gudang: indikator ini digunakan untuk menilai sistem penataan gudang standar yaitu FIFO dan FEFO; 5) Persentase stok mati: yaitu istilah yang digunakan untuk menunjukkan item persediaan obat di gudang yang tidak mengalami transaksi dalam waktu minimal 3 bulan; dan 6) Persentase nilai stok akhir: yaitu nilai yang menunjukkan berapa besar persentase jumlah barang tersisa pada periode tertentu, yang berbanding terbalik dengan nilai TOR.

\section{Pendistribusian obat pada pasien BPJS di RSUP Prof. Dr. R. D. Kandou}

Hasil penelitian mendapatkan antrian yang panjang dan lama. Sebagian pasien/ keluarga mengatakan bahwa pasien tidak mendapatkan obat dengan jumlah yang terdapat dalam resep dan disuruh bolak balik. Obat yang diberikan tidak diikuti dengan pemberian informasi tentang obat. Apoteker dan asisten apoteker sudah melakukan sesuai SOP penerimaan resep atau penyiapan obat yaitu mencantumkan tanggal pembuatan, nama pasien, nama obat, dosis obat, aturan pakai, waktu, dan rute pemberian. Petugas penerima mengisi nama penerima resep, tanda tangan, dan menanyakan nomor tilpon penerima obat. Mengenai penyerahan obat pada pasien terdapat 7 klarifikasi benar, yaitu kejelasan penulis, benar obat, benar waktu dan frekuensi pemberian, benar dosis, benar rute pemberian, benar pasien, serta benar informasi dan dokumentasi. Dengan antrian yang panjang dan resep yang menumpuk kadang kala petugas tidak menginformasi cara minum obat atau rute pemberian obat.

Hasil penelitian ini selaras dengan penelitian oleh Arini et al. $^{7}$ mengenai pengendalian intern terhadap persediaan obat untuk pasien pengguna BPJS kesehatan di RSUD Kabupaten Buleleng menggunakan metode deskriptif kualitatif dengan data primer dan sekunder. Rumah sakit merupakan institusi pelayanan kesehatan bagi masyarakat dengan karakteristik tersendiri yang dipengaruhi oleh perkembangan ilmu pengetahuan kesehatan, kemajuan teknologi, dan kehidupan sosial ekonomi masyarakat yang harus tetap mampu meningkatkan pelayanan yang lebih bermutu. Adanya perubahan pada suatu program kesehatan tertentu merupakan suatu kebutuhan mengenai penerapan pengendalian intern yang cukup intensif karena sangat memengaruhi suatu proses operasional rumah sakit.

Tahap distribusi merupakan tahapan dari siklus manajemen obat yang sangat penting dan kompleks, sedangkan penggunaan obat merupakan tahap yang penting dan menjadi orientasi utama dalam pelayanan kefarmasian. Sasongko ${ }^{8}$ mengevaluasi tahapan pengelolaan obat terutama distribusi dan penggunaan obat pada pasien rawat jalan di Instalasi Farmasi 
Rumah Sakit Ortopedi Prof. Dr. R. Soeharso Surakarta. Pengambilan data dilakukan selama bulan Februari-Maret 2014. Jenis penelitian ialah deskriptif analitik dengan pengambilan data secara retrospektif dan konkuren. Sampel penelitian sebesar 100 pasien dan 660 lembar resep. Hasil evaluasi menunjukkan bahwa belum semua pengelolaan obat pada tahap distribusi dan penggunaan dikelola secara efisien. Indikator yang belum efisien ialah kecocokan jumlah obat dengan kartu stok sebesar 99,33\%, masih terdapatnya stok mati sebesar 3,33\%, peresepan generik masih sebesar $70,18 \%$, dan obat yang diresepkan sesuai formularium rumah sakit sebesar 95,76\%. Faktor-faktor yang memengaruhi kinerja pengelolaan obat antara lain kurangnya ketelitian petugas instalasi logistik dalam pencatatan, kasus penyakit yang jarang, beberapa obat tidak ada generiknya dan tidak semua dokter hafal isi formularium rumah sakit. ${ }^{8}$

Rumah sakit menyalurkan obat melalui pengisian formulir yang paling sederhana untuk memperkecil kemungkinan terjadinya kesalahan dalam pendistribusian dan pemberian. Ketika suatu obat dikeluarkan dari kemasannya yang asli atau disiapkan dan disalurkan dalam bentuk atau wadah (container) yang berbeda dan tidak segera diberikan maka obat harus diberi label dengan nama obat, dosis atau konsentrasi obat, tanggal penyiapan, dan tanggal kadaluwarsa. Farmasi sentral dan titik distribusi obat yang lain di seluruh rumah sakit menggunakan sistem yang sama. Sistem menunjang pengeluaran obat secara akurat dan tepat waktu. ${ }^{9}$

\section{Penarikan obat pada pasien BPJS di RSUP Prof. Dr. R. D. Kandou}

Hasil penelitian mendapatlan bahwa stok obat yang telah mendekati kadaluwarsa segera dipulangkan ke gudang. Pihak gudang melakukan penarikan agar supaya obat dapat dikembalikan ke perusahan obat. Proses penarikan telah mengikuti Permenkes no. 72 tahun 2012, yang menyatakan bahwa penarikan sediaan farmasi yang tidak dapat digunakan harus dilaksanakan dengan cara yang sesuai dengan ketentuan peraturan perundangundangan yang berlaku. Produk yang tidak memenuhi persyaratan mutu atau telah kadaluwarsa tidak memenuhi syarat untuk dipergunakan dalam pelayanan kesehatan atau kepentingan ilmu pengetahuan. ${ }^{3}$

\section{SIMPULAN}

Ketersediaan obat pada pasien BPJS di RSUP Prof. Dr. R. D. Kandou merupakan hasil dari rangkaian yang masuk dalam siklus distribusi obat dengan dukungan komunikasi internal yang cukup dalam proses distribusi selaras dengan standar akreditasi dan Permenkes pelayanan kefarmasian no.72 tahun 2016 .

\section{SARAN}

1. Tingkat pemahaman formularium nasional perlu ditingkatkan sehingga mendekatkan kebutuhan pasien BPJS dengan ketersediaan obat. Bersamaan dengan itu perlu adanya realisasi penggunaan sistem teknologi informasi internal untuk memastikan adanya ketersediaan obat.

2. Perlu adanya penggabungan depo layanan rawat jalan dan rawat inap 24 jam di satu lokasi yang lebih besar, dan menambah counter layanan yang bisa melayani pasien BPJS dengan ini dapat menambah kapasitas layanan dan meratakan tingkat frekuensi layanan farmasi.

\section{DAFTAR PUSTAKA}

1. Febriawati H. Manajemen Logistik Farmasi Rumah Sakit. Yogyakarta: Gosyen Publishing, 2013.

2. Tantangan standar tarif pelayanan kesehatan dalam penyelenggaraan program jaminan kesehatan JKN. Jakarta: Menteri Kesehatan Republik Indonesia, 2014.

3. Standar pelayanan kefarmasian di rumah sakit. Jakarta: Menteri Kesehatan Republik Indonesia, 2017.

4. Yuliastuti F, Achmad P, Riswaka S. Analisis penggunaan obat pada pasien rawat jalan di Rumah Sakit Umum Daerah Sleman Yogyakarta periode 
April 2009. Media Farmasi. 2013;10:104-13.

5. Ibrahim A, Lolo WA, Citraningtyas. Evaluasi penyimpanan dan pendistribusian obat di gudang farmasi RSUP Prof. Dr. R. D. Kandou Manado. Pharmacon. 2016;5(2).

6. Sheina B, Umam MR, Solikah. Penyimpanan obat di gudang Instalasi Farmasi RS PKU Muhammadiyah Yogyakarta Unit I. Kes Mas. 2010;4(1):1-75.

7. Arini L, Sulindawati NLGE, Herawati NT. Analisis pengendalian intern terhadap pertsediaan obat untuk pasien
Pengguna BPJS (Badan Penyelenggara Jaminan Sosial) Kesehatan di RSUD (Runah Sakit Umum Daerah) Kabupaten Buleleng. JIMAT. 2015;3(1).

8. Sasongko H. Evaluasi distribusi dan penggunaan obat pada pasien rawat jalan di Instalasi Farmasi Rumah Sakit Ortopedi Prof. DR. R. Soeharso Surakarta [Tesis]. Yogyakarta: Universitas Gajah Mada, 2014.

9. Standar akreditasi rumah sakit. Jakarta: Kementrian Kesehatan Republik Indonesia, 2012. 